\title{
INFLUENCE OF HUMAN AND BOVINE SUBSTRATE ON THE MICROLEAKAGE OF TWO ADHESIVE SYSTEMS
}

\author{
Karoline Guará Brusaca ALMEIDA ${ }^{1}$, Kristine Guará Brusaca Almeida SCHEIBE ${ }^{1}$, Ana Emília Figuerêdo OLIVEIRA², \\ Cláudia Maria Coêlho ALVES ${ }^{3}$, José Ferreira COSTA²
}

\author{
1- DDS, MSc, Private practice, São Luiz, MA, Brazil. \\ 2- DDS, MSc, PhD, Assistant Professor, Department of Dentistry I, Dental School, Federal University of Maranhão, São Luiz, MA, Brazil. \\ 3- DDS, MSc, PhD, Assistant Professor Department of Dentistry II, Dental School, Federal University of Maranhão, São Luiz, MA, Brazil. \\ Corresponding address: Profa. Dra. Cláudia Maria Coêlho Alves - Rua Sírius, 86 - Portal do Vinhais - 65.078-340 - São Luís, MA - Brasil - \\ Phone: +55-98-3236-0529 - e-mail: cmcoelhoa@ig.com.br
}

Received: February 3, 2008 - Modification: July 10, 2008 - Accepted: August 30, 2008

\begin{abstract}
$\Gamma_{\text {he }}$ and bovine subste deep) were made as follows: 8 cavities were prepared on the buccal and lingual surfaces of the human teeth with margins located on enamel and 16 cavities were prepared on the buccal surfaces of the bovine teeth. The cavities were randomly assigned to 4 groups of 8 cavities according to the adhesive system and substrate: G1 - Prime \& Bond 2.1 (Dentsply)/human substrate; G2 - Adhese (Ivoclar/Vivadent)/human substrate; G3 - Prime \& Bond 2.1 (Dentsply)/bovine substrate; G4 - Adhese (Ivoclar/Vivadent)/bovine substrate. The cavities were filled with microhybrid composite resin (Fillmagic) and after polishing/finishing procedures, the teeth were subjected to a thermocycling regimen of 500 cycles with 1 -min immersions in water at $55^{\circ} \pm 2^{\circ} \mathrm{C}$ and $5^{\circ} \pm 2^{\circ} \mathrm{C}$. Next, the teeth were coated with two layers of nail polish to within $1 \mathrm{~mm}$ of the margin, submerged in a $50 \%$ silver nitrate solution for $2 \mathrm{~h}$, rinsed thoroughly in running tap and immersed in developing solution for $8 \mathrm{~h}$. The restorations were bisected resulting in 16 specimens. Microleakage was observed under a stereomicroscope at $\mathrm{x} 25$ and recorded using four-point (0-3) scoring system. The data were analyzed statistically by the Mann Whitney U-test at 5\% significance level. Leakage was present in all specimens and there was statistically significant difference between the adhesive systems. Adhese self-etching system showed significantly more leakage in both substrates (human $-\mathrm{p}=0.0001$ and bovine $-\mathrm{p}=0.0031$ ). There was no statistically significant difference between human and bovine substrates for either of the adhesive systems based on different bonding mechanisms (Prime \& Bond $2.1-\mathrm{p}=0.6923$ and Adhese - $\mathrm{p}=0.6109$ ). Neither of the adhesive systems was capable to completely prevent microleakage and the self-etching system was more susceptible to microleakage.
\end{abstract}

Key Words: Tooth. Microleakage. Bovine and human teeth. Self-etching adhesives.

\section{INTRODUCTION}

The advances in the dental material science still generate products with a more effective and lasting adhesive ability. Restorative dentistry has taken advantage from this development since cavity preparation tends to be more conservative, which decreases the marginal leakage and the risk of pulpal injuries ${ }^{6,9,25}$. However, the new products on the market need suitable evaluation and clinical assessment has been proven to be difficult due to the need for longitudinal studies. Moreover, high cost is usually associated and professional qualification is required ${ }^{23,27}$.

Two types of substrates have been described as alternatives for adhesion tests: human and bovine teeth $^{1,5,17,18,22}$. Several studies have been performed in human teeth but, currently, due to ethical issues, these teeth have become difficult to find ${ }^{5}$. The use of bovine teeth in in vitro experiments has become frequent because of their histomorphological similarities with human teeth, larger size and ease availability ${ }^{1,17,22,24,30}$. In addition, the storage time, age range and the attainment of intact bovine teeth can be controlled $^{30}$. However, different reports have been cited in literature about the applicability of bovine teeth and other substrates, such as swine teeth, in laboratorial trials ${ }^{1,2,5,6,18,19,20,22}$.

Several studies have investigated microleakage trying to improve the longevity of composite restorations ${ }^{1,22}$. It has been reported the difficulty in obtaining marginal sealing of composite resin restorations at the dentin margin is due to the complexity of this type of the dental tissue. It is known that dentin is a heterogeneous and physiologically dynamic substrate that challenges the bonding ability of the adhesive 
systems, unlike enamel, which is favored by the chemical composition such as mineral salts ${ }^{9}$.

Traditionally, adhesive systems are applied after acid etching. This process removes the smear layer and increases dentin permeability allowing the penetration of the hydrophilic adhesive in order to form a hybrid layer ${ }^{4,19,25}$. Although adhesives using previous etching with phosphoric acid are still widely employed, the fact of causing, in some cases, postoperative sensitivity ${ }^{10,19}$ has led to attempts to replace this procedure ${ }^{3}$. Self-etching adhesive systems are based on the use of non-rinse monomers that etches enamel and partially demineralize the smear layer and subjacent dentin, promoting micromechanical retention into these demineralized structures. This approach facilitates the clinical protocol because it eliminates the rinsing phase after phosphoric acid etching ${ }^{9,14,23}$. Results on the effectiveness of self-etching when compared to etch-and-rinse adhesive systems are contradictory ${ }^{14}$. Some trials show a similarity between these systems $\mathrm{s}^{3,9,30}$, while others suggest a superiority of the total-etching ${ }^{4,14,15,21,23,26}$.

Nevertheless, the causes for leakage are related to several factors, such as adhesive or restorative material degradation and stress induced by the polymerization shrinkage, which result in bond failure around the restorations when they are higher than the bond strength of the adhesives ${ }^{8,10,12,28}$. Further bacterial invasion, postoperative sensitivity, marginal staining, recurrent decay and pulpal necrosis are referred to microleakage leading to most of the failures of esthetic restorations $s^{4,7,11}$

Since many alternatives depend on the development of more efficient adhesive and restorative material ${ }^{10}$, the aim of this study was to evaluate in vitro the marginal sealing of two adhesives systems and to analyze the influence of human and bovine substrates on marginal microleakage in enamel.

\section{MATERIAL AND METHODS}

The present study was approved by the Research Ethics Committee of Presidente Dutra University Hospital - CEP/ HUUFMA (Protocol number 33104-1616/2005). Eight sound human premolar teeth extracted due to orthodontic reasons and 16 bovine incisors kept in saline at $8^{\circ} \mathrm{C}$ before use were examined under a stereomicroscope with magnifying glass $(\times 25)$ in order to discard teeth with signs of enamel cracks or structural failures ${ }^{6}$.

Rectangular-shaped class $V$ cavities with margins located on enamel (4 mm wide x $2 \mathrm{~mm}$ high x $2 \mathrm{~mm}$ deep) were made as follows: 8 cavities were prepared on the buccal and lingual surfaces of the human teeth and 16 cavities were prepared on the buccal surfaces of the bovine teeth. A highspeed diamond bur (KG Sorensen, Barueri, SP, Brazil) was used to prepare the cavities under water coolant (Kavo do Brasil S.A., Joinville, SC, Brazil). The bur was replaced after every five preparations in order to maintain a cutting efficiency. Cavity standardization was obtained by a digital slide gauge.

Human and bovine teeth were randomly assigned to 4 groups of 8 cavities according to the adhesive applied and the type of substrate. After finishing, each group was restored using adhesive systems with different bonding mechanisms: a two-step etch-and-rinse (Prime \& Bond 2.1; Dentsply Ind. e Com. Ltda., Petrópolis, RJ, Brazil) and a two-step selfetching adhesive system (Adhese; Ivoclar/Vivadent, AG, Germany). The cavities were restored and sectioned longitudinally through the center of the restoration obtaining 16 specimens per group (Table 1 ).

The cavities of groups 1 and 3 were etched with $35 \%$ phosphoric acid gel (Dentsply Ind. e Com. Ltda.) for $30 \mathrm{~s}$ in enamel and $15 \mathrm{~s}$ in dentin, rinsed and dried with a mild air stream leaving the surface visibly moist. Then, Prime \& Bond 2.1 was applied for $20 \mathrm{~s}$, gently air dried to removed excess and light cured for $10 \mathrm{~s}$. A second layer was applied in the same way as previously mentioned. In Groups 2 and 4, Adhese primer component was applied for $15 \mathrm{~s}$ and gently air thinned. Next, the adhesive component was applied and the excess was removed with an air jet and light cured for $10 \mathrm{~s}$. All cavities were filled with a microhybrid composite resin (Fill Magic; Vigodent SA Indústria e Comércio, Rio de Janeiro, RJ, Brazil) by the placement of three increments and each one light cured for $40 \mathrm{~s}$. A visible light-curing unit (Curing Light XL 1500, 3M/ESPE, St. Paul, MN, USA) was used at continuous intensity of $460 \mathrm{~mW} / \mathrm{cm}^{2}$.

All specimens were stored in distilled water at $37^{\circ} \mathrm{C}$ for $24 \mathrm{~h}$. The restorations were finished with a sequential series of aluminum oxide disks (Sof-Lex, 3M/ESPE) and stored in distilled water at $37^{\circ} \mathrm{C}$ for $24 \mathrm{~h}$. Next, the specimens were subject to a thermocycling regimen of 500 thermal cycles between $5^{\circ} \mathrm{C}$ and $55^{\circ} \mathrm{C}$ with a dwell time of $60 \mathrm{~s}$ in each temperature and a transfer time of $10 \mathrm{~s}$ between baths. Thereafter, the teeth were sealed with two coats of nail polish leaving $1 \mathrm{~mm}$ from the resin/tooth interface margins and were immersed in a $50 \%$ silver nitrate solution for $2 \mathrm{~h}$. Thereafter, the specimens were rinsed thoroughly under running tap water and were exposed to a developing solution (Kodak, Rochester, NY USA) for $8 \mathrm{~h}$ under fluorescent light and then rinsed again. The human teeth were sectioned longitudinally to a mesiodistal direction through the center of the restoration resulting in two slices for the leakage analysis. The bovine teeth were sectioned buccolingually through the center of the restoration providing two sections for evaluation. The microleakage assessment was recorded by a stereomicroscope with a magnifying glass $\times 25$ (Coleman Com. Imp., Santo André, SP, Brazil). The following criteria were used to score the extent of leakage

TABLE 1- Distribution of the groups according to the adhesive systems and substrates

\begin{tabular}{llcc}
\hline Group & Substrate & Adhesive & $\begin{array}{c}\text { Number of } \\
\text { specimens }\end{array}$ \\
\hline 1 & Human & Prime \& Bond 2.1 & 16 \\
2 & Human & Adhese & 16 \\
3 & Bovine & Prime \& Bond 2.1 & 16 \\
4 & Bovine & Adhese & 16 \\
\hline
\end{tabular}


TABLE 2- Frequency of marginal leakage in the cervical wall in different experimental conditions

\begin{tabular}{|c|c|c|c|c|c|}
\hline \multirow[t]{2}{*}{ Groups } & \multirow[t]{2}{*}{ Substrate/material } & \multicolumn{4}{|c|}{ Scores } \\
\hline & & 0 & 1 & 2 & 3 \\
\hline G1 & Human/Prime \& Bond 2.1 & 10 & 5 & 1 & 0 \\
\hline G2 & Human/Adhese & 1 & 4 & 2 & 9 \\
\hline G3 & Bovine/Prime \& Bond 2.1 & 11 & 5 & 0 & 0 \\
\hline G4 & Bovine/Adhese & 4 & 3 & 0 & 9 \\
\hline
\end{tabular}

TABLE 3- Mean of microleakage and standard deviations for the interaction between the substrates

\begin{tabular}{llll}
\hline & Prime \& Bond 2.1 & Adhese & p value* \\
\hline Human Dentin & $0.438 \pm 0.6292$ & $2.188 \pm 1.0468$ & 0.0001 \\
Bovine Dentin & $0.313 \pm 0.4787$ & $1.875 \pm 1.3601$ & 0.0031 \\
\hline
\end{tabular}

* Mann-Whitney $U$ test $(p<0.05)$.

TABLE 4- Mean of microleakage and standard deviations for the interaction between the adhesive systems

\begin{tabular}{lccc}
\hline & Human Substrate & Bovine Substrate & p value* \\
\hline Prime \& Bond 2.1 & $0.438 \pm 0.6292$ & $0.313 \pm 0.4787$ & 0.6923 \\
Adhese & $2.188 \pm 1.0468$ & $1.875 \pm 1.3601$ & 0.6109 \\
\hline
\end{tabular}

* Mann-Whitney U test ( $p>0.05)$.

evaluated by three calibrated examiners: 0 - no leakage, 1 leakage up to one-third of the gingival wall, 2- leakage up to two-thirds of the gingival wall and 3- leakage onto the axial wall of the cavity. The statistical analysis showed an abnormal distribution by the adherence test to the normality curve and so the data were submitted to the nonparametric Mann-Whitney $U$ test in order to determine the significant differences of microleakage degree for the adhesive systems and substrates. Two-by-two comparisons were done with significance level of $5 \%(a=0.05)$ in this test.

\section{RESULTS}

Marginal leakage results are shown in Table 2. There were statistically significant differences between the adhesive applied. The highest leakages were found for Adhese on both human $(p=0.0001)$ and bovine $(p=0.0031)$ teeth (Table 3). However, no statistically significant differences were detected between the human and bovine substrates for the tested adhesive systems (Prime \& Bond $2.1-p=0.6923$ and Adhese $-p=0.6109$ ) (Table 4).

\section{DISCUSSION}

Regarding the substrate, the findings of the present study are in accordance to those of Reeves, et al. ${ }^{22}$ (1995), Pashley, et al. ${ }^{19}$ (1995), Patierno, et al. ${ }^{20}$ (1997), Nakamichi, et al. ${ }^{17}$ (1983), Coradazzi, et al. ${ }^{5}$ (1998), Soto, et al. ${ }^{24}$ (2000) and Wilder Jr, et al. ${ }^{30}$ (1998), who found good results using bovine teeth and no statistically significant difference between human and bovine enamel. These data confirm that bovine enamel presents tensile and shear bond strength and elastic modulus similar to those of human teeth ${ }^{20}$. The mature enamel of non-erupted bovine teeth is believed to concentrate carbonate slightly higher than that to human teeth, which make bovine substrate more susceptible to acid etching by the variation of atoms in hydroxyapatite crystals ${ }^{22}$. In spite of the differences on density and porosity between human and bovine enamel, bonding mechanism by acid etching is similar ${ }^{24}$.

Other studies have compared human, bovine and swine teeth. The higher leakage was observed in the bovine and swine enamel with significant difference from the human enamel, which indicates that the marginal sealing capacity can be affected by the differences between these substrates, that is, it depends on the origin of enamel ${ }^{1,2,16,18}$. Barkmeier and Erickson ${ }^{2}$ (1994) have found that bond strength to bovine enamel was $35 \%$ lower when compared to human enamel. It is known that, bovine teeth present higher enamel prisms, 
are harsher without acid etching ${ }^{17}$ and have more structural defects than human enamel since the bovine substrate develops fast before and after eruption ${ }^{16}$. According to Abuabara, et al. ${ }^{1}$ (2004) the substrates have shown variations in the histological, chemical, structural and morphological compositions that can cause different leakage behavior in the interaction of the adhesive/substrate system. This would be a reason for significantly higher bond strength for enamel and dentine of the human teeth in comparison to bovine substrate ${ }^{1,18}$

The least desirable results of this investigation for selfetching adhesive systems can probably be explained due to the little acidity of their monomers, which provide a lower degree of demineralization and further infiltrates the enamel surface in a shallow etching depth when compared to phosphoric acid conditioning, then reducing close contact with substrates ${ }^{13}$. Lopes, et al. ${ }^{13}$ (2003) have reported that bovine enamel presents low surface energy when these adhesive systems are applied. This could explain higher leakage values with the self-etching adhesive system.

None of the adhesive systems tested was able to avoid completely leakage at the enamel margin. These findings agree with those of Wilder Jr.,et al. ${ }^{30}$ (1998); Farias et al. ${ }^{6}$ (2002); Hilton ${ }^{10}$ (2002) and Frankenberger, et al. ${ }^{8}$ (2005). This study revealed that the self-etching adhesive system Adhese exhibited higher leakage on both substrates. Likewise, Miyazaki, et al. ${ }^{15}$ (1999) reported that enamel bond strength of self-etching adhesive systems is lower than that of etch-and-rinse adhesive systems. In addition, it can be influenced by the drying time of primer applied before the adhesive. The water contained in the primer in contact with the already wet dental substrate performs as the molecules of being plastic, determining immediate changes in some of their mechanical properties after the adhesive polymerization. ${ }^{4,26}$ Thus, it is advisable to follow the manufacturers' instructions in order to avoid adverse effects in the adhesive interface ${ }^{4,15}$.

As Tay, et al. ${ }^{26}$ (1996) reported, water is an essential component in some current adhesive systems, allowing the preservation of the dried collagen network that will be rewet prior to penetration of the methacrylate compounds. Nevertheless, water-based systems without organic solvents are more susceptible to failure, when the drying step of the substrate is insufficient, which can lead to the dilution of resin compounds reducing the conversion degree and bond strength. Carvalho, et al. ${ }^{4}$ (2004) verified that the conditioning efficacy and the penetration of self-etching adhesive systems in enamel and dentin depend on the initial acidity of the material and the buffering capacity offered by the substrate. It is thus expected that these materials have less effectiveness on enamel due to its higher calcium content ${ }^{4}$. The problems related to the etching potential of the self-etching systems are basically for the self-etching primers (two-step adhesives) because they are considered of mild or moderate aggressiveness $(\mathrm{pH}$ between 1.5 to $3.0)^{5,25}$. However, with the development of more acidic formulations, enamel adhesion became satisfactory, although less than that obtained with the total-etch adhesive systems ${ }^{4}$.
Perdigão and Geraldelli ${ }^{21}$ (2003) found higher shear bond strength to enamel for total-etch than for self-etching adhesive systems. On the other hand, these findings were performed on permanent enamel where some self-etching systems do not promote a satisfactory etching ${ }^{14}$. Some studies have shown that when enamel is not ground the aprismatic layer is maintained, which is a superficial portion of enamel less reactive to acid etching, which can explain an inadequate performance of self-etching adhesive systems, requiring a prior acid etching step or bur-preparation of the enamel surface $^{14}$. IN primary enamel, which seems to be more susceptible to demineralization ${ }^{14,23}$, the self-etching systems may promote good conditioning patterns, resulting in adequate bond strengths ${ }^{14}$.

Contrary to these findings, Barkmeier, et al. ${ }^{3}$ (1995) have noted that the acidic primer is a perfect substitute for the etch-and-rinse adhesive systems in enamel and dentin. Their results have shown that enamel adhesion was significantly higher than dentin adhesion. There was no leakage at the enamel margins and there was minimal leakage in dentin that may be attributed to the fact that self-etching adhesive systems provided higher adhesion and lower leakage values. For Wilder Jr., et al. ${ }^{30}$ (1988), Hewlett ${ }^{9}$ (2003) and Miranda, et al. ${ }^{14}$ (2006), the bonding effectiveness of resins to enamel and dentine using the conventional and simplified adhesive were very similar but the simplified systems had the advantage of reducing the number of clinical steps. The twostep self-etch adhesives, in leakage, are considered gold standard when compared to three-step etch-and-rinse adhesive and even higher than two-step etch-and-rinse adhesive $e^{3,4}$. Taking into account the different sources of results (professional, substrate, material, etc.), it should be emphasized that the self-etching systems, mainly two-step products, are less sensitive to the operative technique and overcome the total etching technique in this issue ${ }^{4}$.

In agreement with the present study, Farias, et al. ${ }^{6}$ (2002) have claimed that the hybridization technique of Prime \& Bond 2.1 did not seem to be effective in the prevention of microleakage. The use of this type of adhesive is not able to provide a hermetic sealing and eliminate microleakage, but it may minimize its occurrence in enamel by controlling the polymerization shrinkage stresses ${ }^{25}$, depending on the restorative material ${ }^{6,28,29}$. With regard to the simplified adhesives, Prime \& Bond 2.1 has been reported to have higher leakage values than Single Bond at both occlusal and gingival walls, though without statistical significance ${ }^{30}$.

In addition, the similarity of the results obtained in both human and bovine substrates highlights the possibility of replacing human teeth by bovine, particularly the enamel structure, facilitating the achievement of dental substrate for laboratory studies and showing that adhesive systems, regardless to the bonding mechanisms, should be used under accurate protocol for operative technique. 


\section{CONCLUSIONS}

Within the limitations of this study it may be concluded that no significant difference was found between the human and bovine teeth regarding the degree of microleakage at the enamel margin. The etch-and-rinse adhesive system had a better performance compared to the self-etching adhesive system on both substrates. Regardless of the substrate, none of the tested adhesive systems was able to prevent microleakage.

\section{REFERENCES}

1- Abuabara A, Santos AJS, Aguiar FHB, Lovadino JR. Evaluation of microleakage in human, bovine and swine enamels. Braz Oral Res. 2004;18(4):312-6.

2- Barkmeier WW, Erickson RL. Shear bond strength of composite to enamel and dentin using Scotchbond Multi-Purpose. Am J Dent. 1994;7(3):175-9

3- Barkmeier WW, Los AS, Triolo PT. Bond strengths and SEM evaluation of Clearfil Liner Bond 2. Am J Dent. 1995;8:289-93.

4- Carvalho RM, Carrilho MR de O, Pereira LCG, Garcia FCP, Marquesini L Jr, Silva SM de A, et al. Adhesive systems: foundations for the comprehension of its application and clinical performance. Bio Odonto Dent Estet. 2004;2(1):9-86.

5- Coradazzi JL, Silva CM, Pereira JC, Francischone CE. Shear bond strength of an adhesive system in human, bovine and swinish teeth. Rev FOB. 1998;6(4):29-33

6- Farias DG de, Avelar RP, Bezerra ACB. Comparative study of the marginal leakage in class V restorations. Pesqui Odontol Bras. 2002;16:838 .

7- Ferracane JL. Status of research on new fillers and new resins for dental composites. In: Proceedings of the International Symposium of Advanced Adhesive Dentistry; 1999; Granada (Spain). Granada: Kuraray; 1999. p. 4-29.

8- Frankenberger R, Pashley DH, Reich SM, Lohbauer U, Petschelt A, Tay FR. Characterisation of resin-dentine interfaces by compressive cyclic loading. Biomaterials. 2005;26(14):2043-52.

9- Hewlett ER. Resin adhesion to enamel and dentin: a review. J Calif Dent Assoc. 2003;31(6):469-76.

10- Hilton TJ. Can modern restorative procedures and materials reliably seal cavities? In vitro investigations [Part 1]. Am J Dent. 2002;15(3):198210 .

11- Kidd EAM. Microleakage: a review. J Dent. 1976;4(5):199-206.

12- Li HP, Burrow MF, Tyas MJ. The effect of long-term storage on nanoleakage. Oper Dent. 2001;26(6):609-16.

13- Lopes MB, Sinhoreti MAC, Correr Sobrinho L, Consani S. Comparative study of the dental substrate used in shear Bond strength tests. Pesqui Odontol Bras. 2003;17(2):171-5.

14- Miranda C, Prates LHM, Vieira RS de, Calvo MCM. Shear bond strength of different adhesive systems to primary dentin and enamel. J Pediat Dent. 2006;31(1):35-40.
15- Miyazaki M, Hirohata N, Takagaki K, Onose H, Moore BK. Influence of self-etching primer drying time on enamel bond strength of resin composites. J Dent. 1999;27:203-7.

16- Moriwaki Y, Kani T, Kozatani T, Tsutsumi S, Shimode M, Yamaga R. The crystallinity change of bovine enamel during maturation. J Dent Mat.1968;9:78-85.

17- Nakamichi I, Iwaku M, Fusayama T. Bovine teeth as possible substitutes in the adhesion test. J Dent Res.1983;62(10):1076-81.

18- Oesterle LJ, Shellhart WC, Belanger GK. The use of bovine enamel on bonding studies. Am J Orthod Dentofacial Orthop. 1998;114(5):514-

19- Pashley DH, Sano H, Ciucchi B, Yoshiyama M, Carvalho RM. Adhesion testing of dentin bonding agents: a review. Dent Mater J. 1995; 11:117-25.

20- Patierno JM, Rueggeberg FA, Anderson RW, Weller RN, Pashley DH. Push-out strength and SEM evaluation of resin composite bonded to internal cervical dentin. Endod Dent Traumatol. 1996;12:227-36.

21- Perdigão J, Geraldeli S. Bonding characteristics of self-etching adhesives to intact versus prepared enamel. J Esthet Restor Dent. $2003 ; 15: 32-42$

22- Reeves GW, Fitchie JG, Hembree JH, Puckett AD. Microleakage of new dentin bonding systems using human and bovine teeth. Oper Dent. $1995 ; 20(6): 230-5$

23- Shimada Y, Senawongse P, Harirattisai C, Burrow MF, Nakaoki Y, Tagami J. Bond strength of two adhesive systems to primary and permanent enamel. Oper Dent. 2002;27(4):403-9.

24- Soto CA, Stanke FC, Rioseco MS. Diente de bovino. Una alternative a los dientes humanos como substrato en investigación. Rev Fac Odont Univ Chile. 2000;18(1):9-29.

25- Swift EJ Jr, Perdigão J, Heymann HO, Ritter AV. Shear bond strengths of one-bottle adhesives to moist enamel. J Esthet Dent. 1999;11(2):1037.

26- Tay FR, Gwinnett AJ, Pang KM, Wei SH. Resin permeation into acidconditioned, moist, and dry dentin - a paradigm using water-free adhesive primers. J Dent Res. 1996;75(4):1034-44.

27- Torii Y, Nishtani Y, Suzuki K. Effect of phosphoric acid etching prior to self-etching primer application on adhesion of resin composite to enamel and dentin. Am J Dent. 2002;15(5):305-8

28- Tyas MJ. Clinical evaluation of five adhesive systems: three-year results. Int Dent J. 1996;46:10-4.

29- Van Meerbeek B, De Munck J, Yoshida Y, Inoue S, Vargas M, Vijay P, et al. Adhesion to enamel and dentin: current status and future challenges. Oper Dent. 2003;28(3):215-35.

30- Wilder AD Jr, Swift EJ Jr, May KN Jr, Waddell SL. Bond strengths of conventional and simplified bonding systems. Am J Dent. 1998;11(3):1147. 